\title{
Christine Peyrard (dir.), Minorités politiques en
} Révolution (1789-1799)

Aix-en-Provence, Publications de l'Université de Provence, coll. Le temps de l'Histoire, 2007

\section{Maxime Kaci}

\section{Q OpenEdition}

1 Journals

Édition électronique

URL : https://journals.openedition.org/ahrf/13023

DOI : $10.4000 /$ ahrf.13023

ISSN : 1952-403X

Éditeur :

Armand Colin, Société des études robespierristes

Édition imprimée

Date de publication : 1 décembre 2013

Pagination : 228-229

ISBN : 978290832789

ISSN : 0003-4436

Référence électronique

Maxime Kaci, «Christine Peyrard (dir.), Minorités politiques en Révolution (1789-1799) », Annales historiques de la Révolution française [En ligne], 374 I octobre-décembre 2013, mis en ligne le 16 janvier 2014, consulté le 01 juillet 2021. URL : http://journals.openedition.org/ahrf/13023 ; DOI : https:// doi.org/10.4000/ahrf.13023

Ce document a été généré automatiquement le 1 juillet 2021.

Tous droits réservés 


\section{Christine PeYRARD (dir.), Minorités politiques en Révolution (1789-1799)}

Aix-en-Provence, Publications de l'Université de Provence, coll. Le temps de l'Histoire, 2007

\section{Maxime Kaci}

\section{RÉFÉRENCE}

Christine PEYRARD (dir.), Minorités politiques en Révolution (1789-1799), Aix-en-Provence, Publications de l'Université de Provence, coll. Le temps de l'Histoire, 2007, 208 p., ISBN 978-2-85399-675-4, $22 €$.

1 Les onze contributions réunies dans cet ouvrage collectif se caractérisent, comme le souligne Christine Peyrard dès l'avant-propos, par une approche neuve, fondée sur une définition dynamique et proprement historique des minorités qui ne sauraient être envisagées comme des catégories intangibles ancrées dans une identité ethnique ou religieuse. L'objectif affiché est d'interroger la manière dont ont été perçues, vécues et analysées des minorités qui fluctuent au gré des contextes locaux, provinciaux ou parlementaires. Au cours de la décennie révolutionnaire caractérisée par des concurrences intenses et des affrontements politiques parfois violents, cette interrogation a pour intérêt majeur d'ouvrir une discussion large sur les représentations politiques et l'apprentissage de la démocratie. Les minorités sont alors définies quantitativement, mais également politiquement comme des groupes subalternes.

2 Dans cette perspective, le passage de la minorité à la majorité par l'accès au pouvoir constitue l'un des enjeux saillants de l'ouvrage. Ainsi, dans une analyse détaillée et particulièrement révélatrice des élections municipales à Aubagne en 1791 et 1792, Cyril Belmonte montre que si la procédure électorale ne pose pas de problème, le refus des résultats enclenche une dynamique de violence et de radicalisation politique. À ce titre, le changement de majorité constitue un moment fondateur. Nathalie Alzas, à partir de 
l'exemple des initiatives royalistes en l'an $\mathrm{V}$ dans l'Hérault, insiste sur les conséquences ambivalentes du recours à la violence qui vise, pour une minorité agissante, à s'affirmer comme majoritaire mais qui finalement s'avère contre-productive car il effraie la population. Cette ambivalence se retrouve à Lyon où la lutte acharnée entre groupes militants Blancs et Rouges en vue d'accéder et de conserver le pouvoir structure, selon Bruno Benoît, la vie politique locale durant une décennie. Cet affrontement suscite le rejet d'une majorité modérée d'habitants qui finit par soutenir Bonaparte.

Un deuxième apport de cet ouvrage relève de ce que l'on pourrait appeler l'imputation de minorité, c'est-à-dire, les efforts menés par des groupes restreints pour disqualifier, en paroles mais aussi en images (Michel Vovelle), leurs adversaires assimilés à des factieux ou encore à des anarchistes (Marc Deleplace). La pratique complémentaire consiste pour des minorités politiques agissantes à accroître leur légitimité en tentant d'incarner la volonté du plus grand nombre et la défense du Salut public. Des tentatives perceptibles tant dans le discours d'Hébert du 21 juillet 1793, reconstitué et analysé par Jacques Guilhaumou, que dans les débats parlementaires de l'an III comme le soulignent Françoise Brunel et Yannick Bosc.

4 À ces contributions sur les enjeux révolutionnaires français, Annie Jourdan offre un contrepoint suggestif à partir des législateurs atypiques de la Révolution batave en montrant combien l'étude des minorités est féconde et permet de comprendre l'émergence d'alternatives politiques originales. Toutefois si des groupes militants ou des ensembles plus larges, exclus de la citoyenneté active tels que les femmes (Martine Lapied), sont l'objet d'études détaillées qui en restituent la composition hétérogène et les modes d'action variés, des difficultés subsistent parfois à se départir des analyses binaires où la majorité rapidement évoquée tend à être assimilée à un bloc. Cet ouvrage n'en demeure pas moins précieux pour comprendre les dynamiques d'affrontements politiques et les stratégies d'acteurs minoritaires divers, il offre une contribution importante à la remise en cause des conclusions péremptoires et souvent désincarnées sur l'incapacité des révolutionnaires à penser le pluralisme. 